\title{
Assessing the Contribution of Self-Monitoring Through a Commercial Weight Loss App: Mediation and Predictive Modeling Study
}

Gregory Farage $^{1^{*}}, \mathrm{PhD}$; Courtney Simmons ${ }^{1 *}, \mathrm{MPH}$; Mehmet Kocak ${ }^{1}, \mathrm{PhD}$; Robert C Klesges ${ }^{1,2}, \mathrm{PhD}$; G Wayne Talcott $^{1,2}$, PhD; Phyllis Richey ${ }^{1}$, PhD; Marion Hare ${ }^{1}$, MS, MD; Karen C Johnson ${ }^{1}$, MPH, MD; Saunak Sen ${ }^{1}$, PhD; Rebecca Krukowski ${ }^{1}$, PhD

${ }^{1}$ Department of Preventive Medicine, College of Medicine, University of Tennessee Health Science Center, Memphis, TN, United States

${ }^{2}$ Center for Addiction Prevention Research, Department of Public Health Sciences, University of Virginia, Charlottesville, VA, United States

* these authors contributed equally

\section{Corresponding Author:}

Rebecca Krukowski, PhD

Department of Preventive Medicine

College of Medicine

University of Tennessee Health Science Center

66 N Pauline St

Memphis, TN, 38163

United States

Phone: 19014482426

Email: rkrukows@uthsc.edu

\section{Abstract}

Background: Electronic self-monitoring technology has the potential to provide unique insights into important behaviors for inducing weight loss.

Objective: The aim of this study is to investigate the effects of electronic self-monitoring behavior (using the commercial Lose It! app) and weight loss interventions (with differing amounts of counselor feedback and support) on 4- and 12-month weight loss.

Methods: In this secondary analysis of the Fit Blue study, we compared the results of two interventions of a randomized controlled trial. Counselor-initiated participants received consistent support from the interventionists, and self-paced participants received assistance upon request. The participants $(\mathrm{N}=191)$, who were active duty military personnel, were encouraged to self-monitor their diet and exercise with the Lose It! app or website. We examined the associations between intervention assignment and self-monitoring behaviors. We conducted a mediation analysis of the intervention assignment for weight loss through multiple mediators - app use (calculated from the first principal component [PC] of electronically collected variables), number of weigh-ins, and 4-month weight change. We used linear regression to predict weight loss at 4 and 12 months, and the accuracy was measured using cross-validation.

Results: On average, the counselor-initiated-treatment participants used the app more frequently than the self-paced-treatment participants. The first PC represented app use frequencies, the second represented calories recorded, and the third represented reported exercise frequency and exercise caloric expenditure. We found that 4-month weight loss was partially mediated through app use (ie, the first PC; 60.3\%) and the number of weigh-ins (55.8\%). However, the 12-month weight loss was almost fully mediated by 4-month weight loss $(94.8 \%)$. Linear regression using app data from the first 8 weeks, the number of self-weigh-ins at 8 weeks, and baseline data explained approximately $30 \%$ of the variance in 4-month weight loss. App use frequency (first PC; $P=.001)$, self-monitored caloric intake (second PC; $P=.001$ ), and the frequency of self-weighing at 8 weeks $(P=.008)$ were important predictors of 4-month weight loss. Predictions for 12-month weight with the same variables produced an $R^{2}$ value of $5 \%$; only the number of self-weigh-ins was a significant predictor of 12-month weight loss. The $R^{2}$ value using 4-month weight loss as a predictor was $31 \%$. Self-reported exercise did not contribute to either model (4 months: $P=.77 ; 12$ months: $P=.15$ ).

Conclusions: We found that app use and daily reported caloric intake had a substantial impact on weight loss prediction at 4 months. Our analysis did not find evidence of an association between participant self-monitoring exercise information and weight 
loss. As 12-month weight loss was completely mediated by 4-month weight loss, intervention targets should focus on promoting early and frequent dietary intake self-monitoring and self-weighing to promote early weight loss, which leads to long-term success.

Trial Registration: ClinicalTrials.gov NCT02063178; https://clinicaltrials.gov/ct2/show/NCT02063178

(JMIR Mhealth Uhealth 2021;9(7):e18741) doi: $\underline{10.2196 / 18741}$

\section{KEYWORDS}

weight loss; self-monitoring; obesity; apps; behavioral intervention

\section{Introduction}

\section{Background}

Consistent dietary and physical activity self-monitoring is an important component of successful weight loss in both traditional in-person behavioral weight loss programs [1,2] and technology-based programs [2-5]. Technology may also increase self-monitoring adherence [2,6-8]. Perhaps because technology-based dietary and physical activity self-monitoring requires minimal effort [9], commercial technology-based dietary and physical activity monitoring programs have grown in quantity and popularity with apps such as Lose It!, which has reported more than 30 million downloads to date, and MyFitnessPal, which had 225 million users in 2018 [10,11].

Self-weighing is another form of self-monitoring that facilitates weight loss [12-14], perhaps because of the behavioral changes in diet or exercise that occur as participants become more aware of their weight trajectories $[15,16]$. Until recently, many studies involving self-weighing relied on questionnaires in which participants could specify their weighing frequency [12]; now, it is possible to directly measure adherence to self-weighing through smart scales that record a participant's weight and self-weighing habits and transmit this information through wireless cellular technology.

Early performance (ie, self-monitoring adherence and weight loss) in a weight loss program is an indicator of long-term weight loss [17-20]. Tsai et al [17] showed that more detailed food records before randomization led to greater weight loss at 1 year. Similarly, Krukowski et al [19] found that early dietary and physical activity self-monitoring is a predictor of weight loss success. In a study by Unick et al [20], weight change at 2 months was predictive of weight change 8 years later. Early identification of participants who are not self-monitoring and who may be at most risk of not losing weight gives clinicians and researchers the opportunity to target those falling behind with additional resources.

\section{Objectives}

The first aim of our investigation was to increase our understanding of self-monitoring behaviors that lead to successful weight loss by using a commercial weight loss app, Lose It!. The second aim was to study if app use predicted weight loss at 4 and 12 months using participant data at an early stage (eg, 4 weeks, 8 weeks, and 4 months) to better identify individuals who might need early attention. As the app use data were composed of many interrelated variables, we summarized the variables using principal component analysis (PCA), which also addresses multicollinearity. We implemented a mediation analysis under the counterfactual framework to understand the mechanism of action of intervention assignment on weight loss at 4 and 12 months. We performed linear regression models with variables from the PCA analysis from the first 4 and 8 weeks of this study to predict weight loss at 4 and 12 months in the participants.

The prediction analysis allowed us to statistically model the relationship between the weight loss variables (at 4 and 12 months) and our set of independent predictors. It revealed the relationships among the variables; however, it did not indicate whether these relationships are causal. The complementary mediation analysis permitted us to make causal inferences about the effect of treatment assignment on weight loss through the mediators.

\section{Methods}

\section{Study Design}

This is a secondary analysis of the Fit Blue study, which was adapted from the Look AHEAD (Action for Health in Diabetes) Intensive Lifestyle Intervention [21-23] for a military lifestyle. The participants were randomly assigned to 1 of 2 treatment groups using a randomized block design with block size 4 [24]. The 2 treatment groups, counselor-initiated treatment and self-paced treatment, differed in the amount of self-initiation required to receive treatment. The counselor-initiated group received 28 phone calls over 12 months with counselors, regular feedback through email on their self-monitored entries on the same schedule as their phone sessions, 28 lesson materials, meal replacements, individualized detailed exercise and meal plans, and access to materials such as food scales, exercise videos, resource books, and cookbooks. They were also encouraged to participate in four challenges to boost their motivation. The self-paced participants could receive the same number of phone sessions and email feedback as the counselor-initiated participants upon request. The self-paced participants also had access to lesson materials and exercise and meal plans, although they had to initiate the request for assistance. Further details about the study design, meal replacements, and study website can be found elsewhere [24]. The main outcome as well as the treatment engagement outcomes have been previously published [25].

The behavioral change goals were standard across the two conditions. All participants were asked to record their daily dietary intake and physical activity for 12 months on the Lose It! app or website. Lose It! premium accounts were created for all participants. They were encouraged to track their diet, caloric 
intake, and exercise using the app. The Lose It! app gave the participants access to a database with more than 7 million foods and corresponding nutritional information [26]. They were encouraged to lose $10 \%$ or more of their initial body weight at a rate of 1-2 pounds per week. Participants with a starting weight of less than $79 \mathrm{~kg}$, between $79 \mathrm{~kg}$ and $97.5 \mathrm{~kg}$, and more than $97.5 \mathrm{~kg}$ were given daily calorie goals of $1200-1300 \mathrm{kcal}$, 1500-1600 kcal, and 1800-1900 kcal, respectively. All participants were given a daily goal of consuming no more than $30 \%$ of calories from fat. In addition, the participants received a personalized exercise plan based on their self-reported physical activity at the baseline visit. They were asked to gradually increase aerobic exercise from their current level reported at baseline until reaching 225-250 minutes weekly, at which point they were to maintain this amount of exercise. A BodyTrace e-scale was provided to each participant, and they were requested to self-weigh daily. In addition, they were asked to attend two in-person follow-up data collection visits at 4 and 12 months.

\section{Participants}

A total of 248 active duty military personnel at Joint Base San Antonio (previously named Lackland Air Force Base) in San Antonio, Texas, participated in the Fit Blue study [24]. To be eligible to participate, participants had to meet the following criteria: aged 18 years or older, BMI of $25 \mathrm{~kg} / \mathrm{m}^{2}$ or more, access to a computer and email, and clearance from a health care provider. In addition, 1 week of monitoring dietary intake and physical activity on Lose It! was required for eligibility [24,27].

Participant recruitment began in December 2013 and ended in March 2016. The Fit Blue study was approved by the institutional review board of the Wilford Hall Ambulatory Surgical Center and acknowledged by the institutional review board of the University of Tennessee Health Science Center. The study approval was maintained over the course of the study, and a data and safety monitoring officer reviewed the accumulated data.

\section{Measures}

\section{Physical Measurements}

The primary outcome was weight change (in kilograms) measured on a calibrated scale (Tanita BWB-800S) in street clothes and without shoes. Height (in centimeters) was measured without shoes using a wall-mounted stadiometer. These measures were recorded at the baseline, 4-month weigh-in, and 12-month data collection visits. Our outcome variable, that is, weight loss, was modeled as the log ratio of the final weight at
4 and 12 months over the baseline weight. We log-transformed the weight change to stabilize variance and address the skewness of the distribution. As we are mostly interested in the participant's achievement, the weight loss ratio was classified as success $(\geq 5 \%$ loss $)$, some loss $(2.3 \%-5 \%)$, or no loss $(<2.3 \%)$. A $5 \%$ weight loss represents a benchmark at which point clinical benefits are observed [28]. Weight loss of less than $2.3 \%$ (or approximately $2.3 \mathrm{~kg}$ ) has been used in previous research to denote weight stability [29].

\section{Weight Self-Monitoring Behaviors}

The participants were asked to monitor their weight daily using the BodyTrace e-scale. The time-stamped weights were transmitted to the study team over cellular technology, and they were also uploaded to each participant's personalized website to view their progress. The self-weighing variable represents the number of days the participants weighed themselves using the BodyTrace e-scale. We included only the plausible values filtered by the True Profile Finder algorithm [30].

\section{Sociodemographic Characteristics}

Age, education level, race, and gender were collected through a baseline questionnaire.

\section{Dietary and Physical Activity Monitoring Behaviors}

The participants recorded their daily consumption (ie, food and beverage items along with their calories) and exercise (ie, type and duration) using Lose It!. The participants were able to log food items for meals, snacks, and beverages, as well as exercise type and volume. They could also use the app to log their weight, which was counted as logging but not as the self-weighing variable. A total of 9 logging-specific measures were calculated to quantify logging behavior, and six caloric measures were estimated to assess caloric intake. We measured the average of the total number of days each week that participants logged at least 1 entry for food, beverage, exercise, or weight.

The independent variables included in the analysis (Figure 1) were categorized into two groups: baseline variables and electronically collected variables. The baseline variables consisted of age and treatment assignment. The electronically collected variables consisted of the frequency of 16 self-weighing and Lose It! app variables (Textbox 1). Each of the measures was calculated for a specific time period (ie, the first 4 weeks, the first 8 weeks, 4 months, and 12 months) depending on the analysis. The time periods used are mentioned in the analysis sections. 
Figure 1. Diagram of variables used in prediction models and mediation analysis.

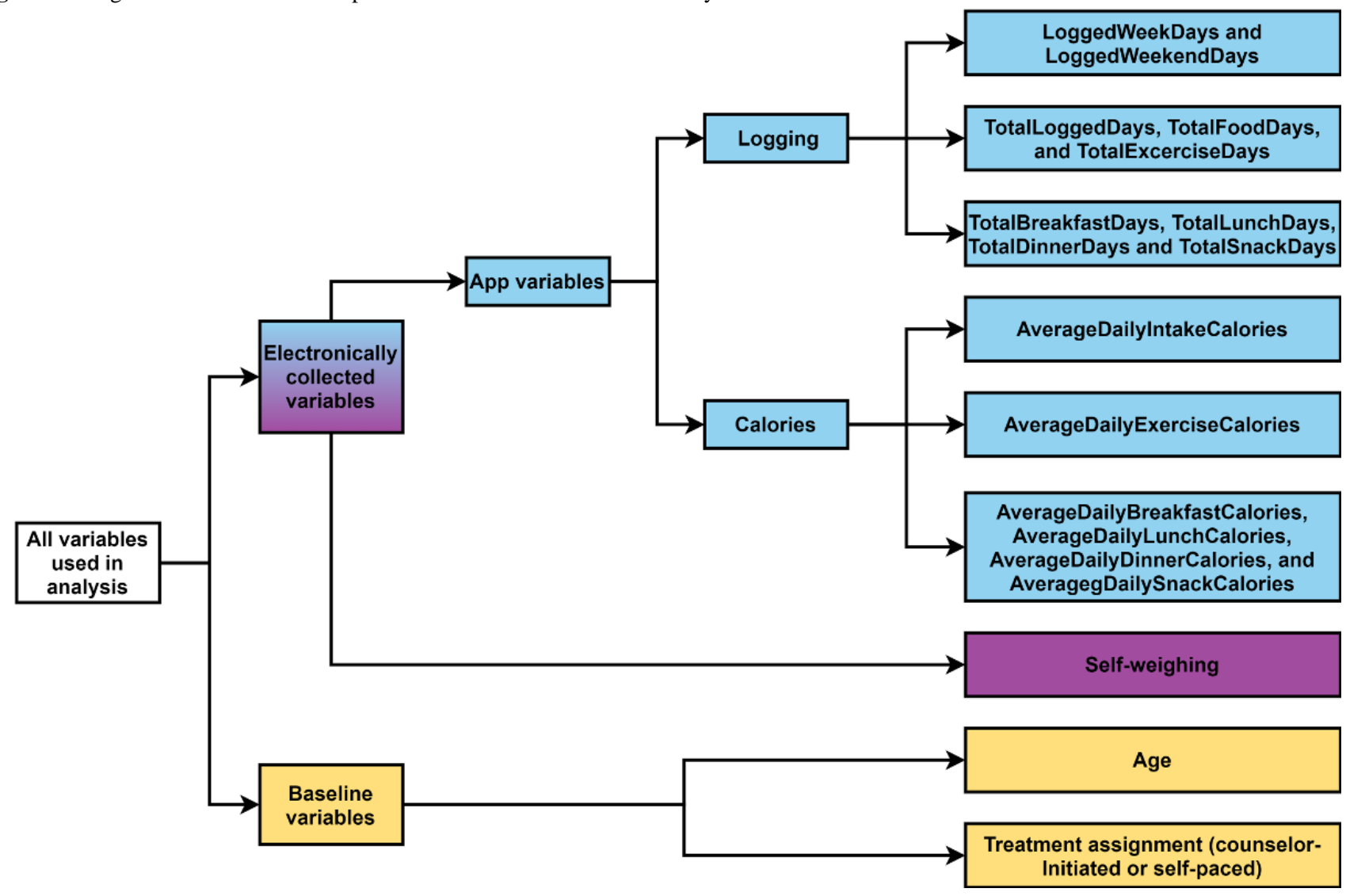

Textbox 1. Description of the electronically collected variables.

\section{Logging measures}

- LoggedWeekDays and LoggedWeekendDays are the number of weekdays and weekend days, respectively, that include at least 1 entry for food, beverage, exercise, or weight.

- TotalLoggedDays is the total number of days with at least 1 entry for food, beverage, exercise, or weight.

- TotalFoodDays is the total number of days with at least 1 food or beverage entry.

- $\quad$ TotalExerciseDays is the total number of days with at least 1 entry for exercise.

- TotalBreakfastDays, TotalLunchDays, TotalDinnerDays, and TotalSnackDays are the total number of days with at least 1 entry for breakfast, lunch, dinner, and snack, respectively.

\section{Caloric measures}

- AverageDailyIntakeCalories is the average daily intake of calories from food over the total number of days with at least 1 food entry. The entries for daily calories that exceeded an upper bound (ie, $4000 \mathrm{kcal}$ for women and $5000 \mathrm{kcal}$ for men) and lower bound (ie, $600 \mathrm{kcal}$ for women and $800 \mathrm{kcal}$ for men) were excluded for implausibility [31].

- AverageDailyExerciseCalories is the average daily calories burned through exercise over the total number of days with at least 1 entry for exercise.

- AverageDailyBreakfastCalories, AverageDailyLunchCalories, AverageDailyDinnerCalories, and AverageDailySnackCalories are the average daily caloric intake values over the total number of days with at least 1 entry for breakfast, lunch, dinner, and snack, respectively.

\section{Statistical Analysis}

\section{Overview}

The analysis was conducted using $\mathrm{R}$ version 4.0.4 [32]. We summarized the data and created graphics for descriptive analysis using the tidyverse package (version 1.3.0) [33]. Descriptive statistics were calculated to examine changes in logging frequency over the course of the study. We considered all sociodemographic variables collected for analysis and included them only if they were associated with a $P$ value of .20 or less with the weight loss outcome. Using this criterion, only age was included in the final analysis.

\section{Loss to Follow-up}

As this is a longitudinal study, not all individuals' weights were observed at the 4- and 12-month visits. Our main analysis included only individuals with complete weight data. However, we also investigated the sensitivity of the effect of the missing 
data using three different analyses. In the last observation carried forward analysis, we assumed that there was no change in the participants' weight after missing a visit. With a more conservative approach, the baseline observation carried forward analysis assumption is that the participants who missed a visit returned to their baseline weight. Neither method showed a substantial difference in the outcome. The results are detailed in the supplemental material available on a GitHub repository [34].

\section{Principal Component Analysis}

We performed a PCA on the Lose It! app variables to reduce the number of variables considered and still capture the useful information in these variables. The PCA also had the additional advantage of addressing multicollinearity in the variables [35]. Each principal component (PC) was a linear combination of the original variables and was uncorrelated with the other PCs. The PC that captured the largest variance was called the first PC, and the $\mathrm{PC}$ that captured the second largest variance was called the second PC, and so on [36,37]. In our case, we had 15 electronically collected variables, of which some were highly correlated with each other. The PCA reduced the number of uncorrelated variables to a much smaller number. We used the packages FactoMineR (version 2.4) [38] and factoextra (version 1.0.7) [39] to obtain the PCs and the new uncorrelated variables. We used a scree plot to determine the number of PCs to include in the analysis. The PCs that jointly explained $70 \%$ of the variance in the data were included in the analysis. Depending on the analysis of interest, PCA was applied to the variables measured over a specific period. Textbox 2 specifies these periods and the data used in the corresponding analyses.

Textbox 2. Time period for the electronically collected variables according to the analysis.

\author{
Mediation for 4-month weight loss \\ - $\quad$ Baseline to 4 months \\ Mediation for 12-month weight loss \\ - $\quad$ Baseline to 12 months \\ Prediction of the 4-month weight loss \\ - Baseline to 4 weeks or baseline to 8 weeks data \\ Prediction of the 12-month weight loss \\ - Baseline to 4 weeks or baseline to 8 weeks data
}

To identify the most important variables that explain the variations in our data, we studied the quality of the representation and the contribution of the variables. The quality of representation of a variable is determined by the square of the correlation coefficient between a variable and a PC. The contribution of a variable for a given PC is estimated by the ratio of its squared correlation coefficient over the sum of all squared correlation coefficients between each variable and the given component [39].

\section{Mediation}

We conducted a causal mediation analysis to understand whether, and how much of, the intervention assignment effect on weight loss operates through intermediate variables such as app use and self-weighing frequency. Figure 2 depicts the hypothesized causal framework underlying our mediation analysis. The analysis was based on a counterfactual framework using a linear regression analytic approach [40]. Simply put, this framework partitions the total effect (TE) of the intervention assignment into the sum of the average causal mediation effect (ACME) and average direct effect. It can be shown that this approach can be used with both linear and nonlinear models and is equivalent to the traditional approach of MacKinnon et al [41] when some conditions hold [42]. In the counterfactual framework, we need to assume two statements to make valid inferences about the causal mediation analysis. This assumption is known as the sequential ignorability assumption. First, the treatment variable is statistically independent of the outcome and mediator variable; second, the mediator is independent of the outcome, given the observed exposure and pretreatment confounders. The counterfactual framework introduced by Imai et al [42] allows us to assess the robustness of our causal conclusions with respect to the violation of the sequential ignorability assumption. To establish if any association existed between the intervention assignment variable and the outcome of weight loss (at 4 and 12 months) and each mediator, we used the two-tailed $t$ statistic. Significance was established using 10,000 permutations. In the causal mediation analysis [42], if the treatment assignment has no effect on the mediator, then the causal mediation effect is zero. The randomized exposure variable (ie, intervention assignment) has two states: self-paced or counselor-initiated. We conducted two mediation analyses for two outcomes: the 4-month weight loss and the 12-month weight loss. In the first mediation analysis, we considered two mediators of the 4-month weight loss: app use (calculated from the first PC of the electronically collected variables) and the frequency of self-weighing. In the second mediation analysis, we considered the mediation of the 12-month weight loss by the 4-month weight loss itself (Figure 2). 
Figure 2. Diagram representing our causal model for treatment assignment, mediators, and outcomes. Arrows show the direction of causation. Dashed arrows represent mediated effects, and solid arrows represent direct effects. a: Causal model for the 4-month weight loss outcome. b: Causal model for the 12-month weight loss outcome.

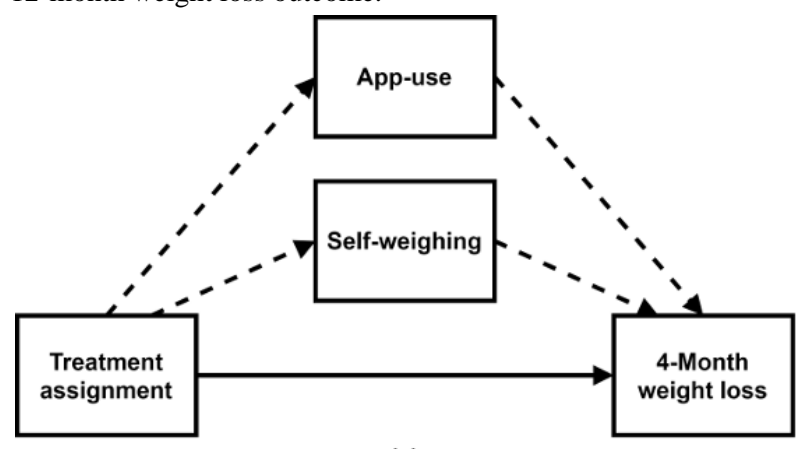

(a)

The mediation analysis included all the data accumulated during the entire study, up to 4 months and 12 months, according to the period of interest. In all models for mediation, we included baseline covariates (age). To estimate the ACME (ie, indirect effect) and the average direct effect from the model-based causal mediation analysis, we used the package mediation (version 4.5.0) [43]. The uncertainty estimates were computed using a nonparametric bootstrap $[43,44]$ with 10,000 simulations. The main motivation is not only to investigate whether a mediation exists, but also to determine if it is partially or fully mediated. It is fully mediated only if the direct effect is zero and partially mediated otherwise. As we had multiple mediators, we were interested in identifying the mediator that conveyed the greatest effect on weight loss [40,45-47].

\section{Weight Loss Predictions Through Linear Regression}

We used the mediation results to guide our variable selection process for the prediction. Five models were considered for 4-month weight loss, and six models were considered for 12-month weight loss. These models used a combination of baseline and electronically collected variables (ie, frequency of self-weighing and app variables summarized by PCA) as predictor variables. We predicted 4-month weight loss and 12-month weight loss using three different sets of predictor variables: (1) only baseline variables (ie, age and treatment assignment), (2) only electronically collected variables from the first 4 weeks, and (3) baseline and electronically collected variables from the first 4 weeks combined. The latter two models were repeated using electronically collected variables from the first 8 weeks. Finally, we considered one more model for 12-month weight loss using 4-month weight loss as the only predictor variable.

We used five-fold cross-validation to evaluate the linear regression models. The PCA was conducted using four out of five folds, including samples with a response value and incomplete samples without response values [48]. The resulting PCs were used to create a linear regression model. The model

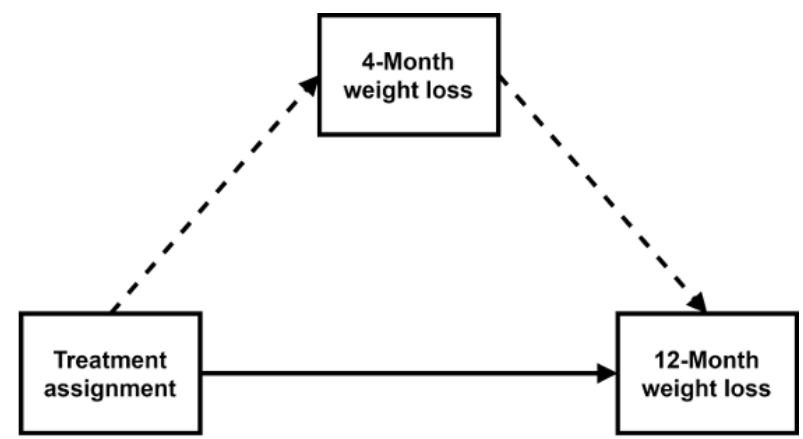

(b)

predicted log weight loss for the fifth fold composed of complete samples. This process was repeated until all participants' weight loss was predicted. We categorized actual and predicted weight loss values as successful weight loss, some loss, or no loss. Prediction accuracy was evaluated using $R^{2}$, the Spearman rank correlation coefficient $(\rho)$, and the multi-class area under the receiver operating characteristic curve (AUC) value. The folds and cross-validation were performed using the caret package (version 6.0-80).

\section{Results}

\section{Overview}

Owing to technical problems when downloading the data for 57 of the participants, 191 of the 248 randomized subjects were included in the analysis (including 103 in the counselor-initiated treatment and 88 in the self-paced treatment). Approximately $80.6 \%(154 / 191)$ of the participants attended the 4-month data collection visit, and approximately $80.1 \%$ (153/191) participated in the 12-month data collection visit. The study demographics are summarized in Table 1. At 4 months, the counselor-initiated treatment lost an average of $3.7 \mathrm{~kg}$ (SD 3.6), and the self-paced treatment lost $0.6 \mathrm{~kg}$ (SD 3.1). At 12 months, the counselor-initiated treatment lost $2.4 \mathrm{~kg}$ (SD 5.0) on average, and the self-paced treatment gained $0.2 \mathrm{~kg}$ (SD 5.1). Figure 3 shows the differences in the number of days with at least 1 item logged per week between the treatment groups. The counselor-initiated treatment 's average number of days with at least 1 item logged (ie, food, beverage, exercise, or weight entries) decreased from 6.48 days per week (week 1) to 5.03 days per week (week 16) over the first 4 months of the study and dropped to 0.70 days per week (week 52) by 12 months. The logging instances for the self-paced treatment decreased from 5.55 days per week (week 1) to 1.99 days per week (week 16) at 4 months and finally to 0.01 days per week (week 52) days by 12 months. 
Table 1. Demographics of counselor-initiated and self-paced participants $(\mathrm{N}=191)$.

\begin{tabular}{|c|c|c|c|c|}
\hline Characteristics & $\begin{array}{l}\text { Counselor-initiated participants } \\
(\mathrm{n}=103)\end{array}$ & Self-paced participants $(\mathrm{n}=88)$ & Total $(\mathrm{N}=191)$ & $P$ value \\
\hline Gender, n (\%) & & & & .99 \\
\hline Female & $53(51.5)$ & $46(52.3)$ & $99(51.8)$ & \\
\hline Male & $50(48.5)$ & $42(47.7)$ & $92(48.2)$ & \\
\hline Race, $n(\%)$ & & & & .66 \\
\hline Black or African American & $22(21.4)$ & $16(18.2)$ & $38(19.9)$ & \\
\hline White & $65(63.1)$ & $61(69.3)$ & $126(65.9)$ & \\
\hline Other & $16(15.5)$ & $11(12.5)$ & $27(14.1)$ & \\
\hline Education, $\mathbf{n}(\%)$ & & & & .55 \\
\hline Less than college & $46(44.7)$ & $44(50)$ & $90(47.1)$ & \\
\hline College or above & $57(55.3)$ & $44(50)$ & $101(52.9)$ & \\
\hline BMI $\left(\mathrm{kg} / \mathrm{m}^{2}\right), \mathbf{n}(\%)$ & & & & .37 \\
\hline Overweight (BMI 25-29.9) & $51(49.5)$ & $37(42)$ & $88(46.1)$ & \\
\hline Obese $(\mathrm{BMI} \geq 30)$ & $52(50.5)$ & $51(58)$ & $103(53.9)$ & \\
\hline Age (years), mean (SD) & $35.5(8.2)$ & $33.9(6.8)$ & $34.8(7.6)$ & .14 \\
\hline
\end{tabular}

Figure 3. Number of days per week with at least one logging (by week and treatment groups) during the first 4 months.

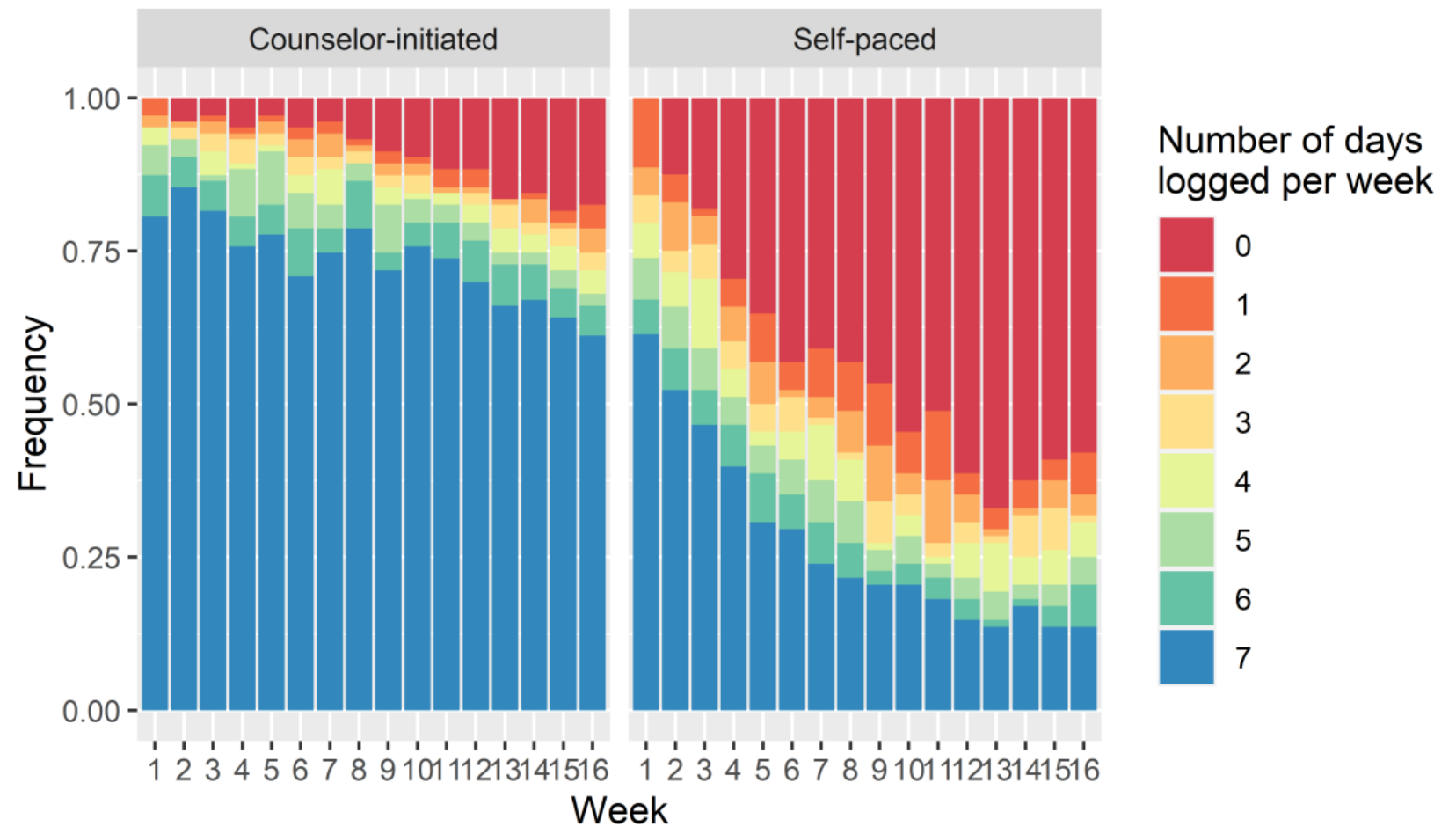

The app variables were summarized using PCA with data from the first 4 and 8 weeks. A total of $72.8 \%$ of the variation in the 8 -week data was captured in the first two components.

Although the PCs are linear combinations of the original variables, they have some interpretive value, that is, we still preserved some cohesive interpretations of the three first PCs. Figure 4 shows that $\mathrm{PC}_{1}$ mainly comprises app variables describing the frequency with which the participants used the app; therefore, we labeled $\mathrm{PC}_{1}$ app-use, and it explains $57.5 \%$ of the variance. $\mathrm{PC}_{2}$ mostly describes daily caloric intake that was self-monitored by the participants, and it explains $15.3 \%$ of the variance. We labeled $\mathrm{PC}_{2}$ app-calories. The inclusion of $\mathrm{PC}_{3}$ explains $9.4 \%$ of the variance $(82.2 \%$ total), and because this component represents the participants' exercise self-monitoring, it is labeled app-exercise. 
Figure 4. The contribution of variable results (top) for the first 3 PCs from the 8 -week PC analysis runs on a scale of 0 to 100 . The darker and larger a circle, the more it contributed to a PC. The quality of the representation of variable results (bottom) are on a scale of 0 to 1 . The darker and larger a circle, the more it is represented by a PC compared with other PCs. PC: principal component.

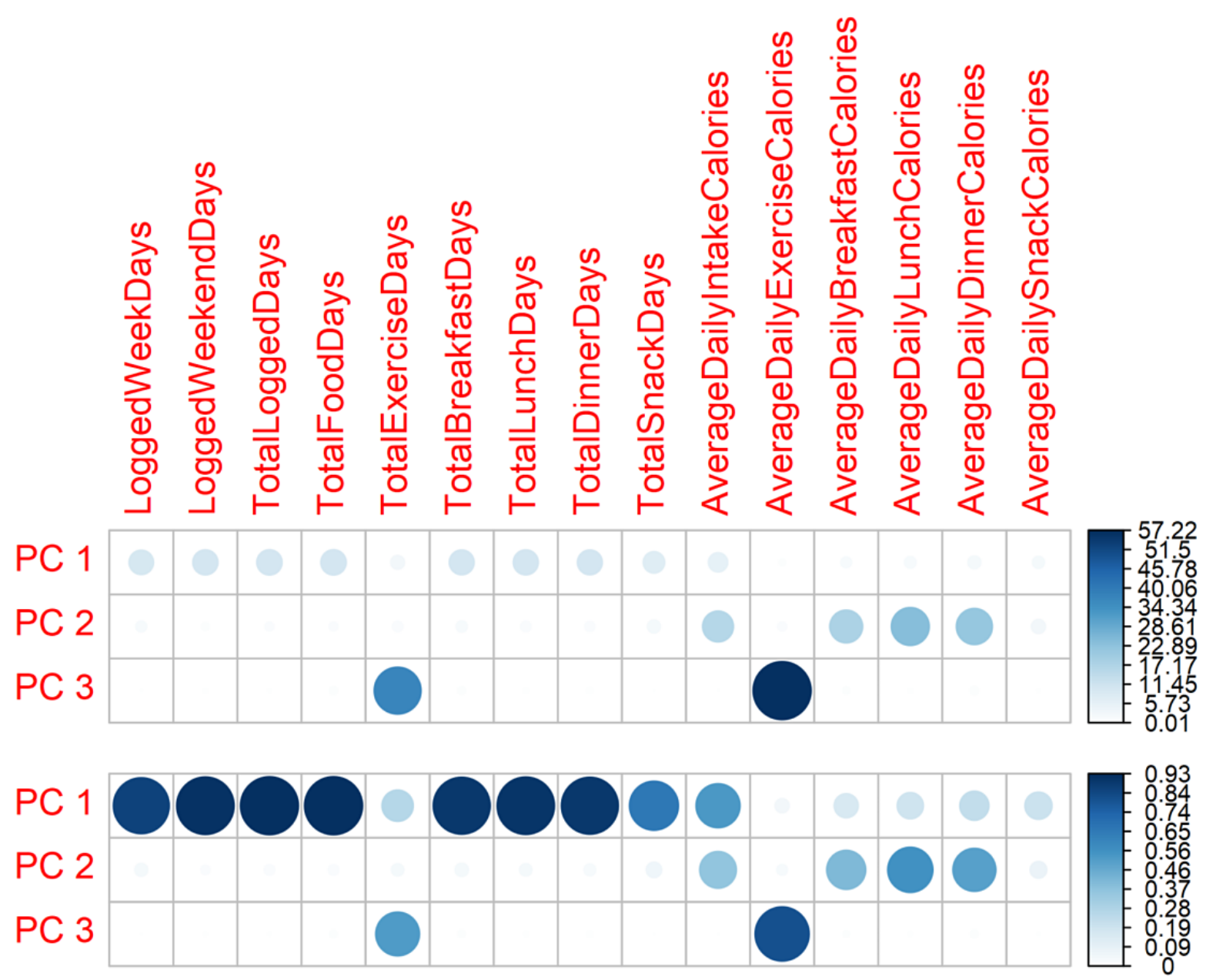

\section{Mediation}

We estimated the significance of the relationship between the intervention assignment variable (self-paced or counselor-initiated) and weight loss for two different periods (ie, baseline to 4 months and baseline to 12 months). There was a significant relationship between the treatment assignment variable (self-paced or counselor-initiated) and weight loss at 4 months $(P<.001)$ and 12-months $(P=.002)$.

For the two periods of interest (4 months and 12 months), treatment assignment was significantly associated $(P<.001)$ with each mediator: the app-use component $\left(\mathrm{PC}_{1}\right)$, the app-calories component $\left(\mathrm{PC}_{2}\right)$, self-weighing frequency, and 4-month weight loss. However, treatment assignment was not associated with the app-exercise component $\left(\mathrm{PC}_{3} ; P=.73\right)$. We considered only app-use $\left(\mathrm{PC}_{1}\right)$ as a mediator because it explained more than $50 \%$ of the variance by itself in comparison with app-calories $\left(\mathrm{PC}_{2} ;<20 \%\right)$ and app-exercise $\left(\mathrm{PC}_{3} ;<10 \%\right)$, which explained a much smaller proportion of the variance.

During the first 4 months (Table 2), we found that the indirect intervention's effect on weight loss transmitted through app-use $\left(\mathrm{PC}_{1}\right)$ and self-weighing frequency roughly accounted for $60 \%$ and $55 \%$ of the TE, respectively. For weight loss at 12 months, the indirect effect (ACME: 0.030, 90\% CI 0.0017-0.046) through the 4-month weight loss accounted for $94 \%$ of the TE. The TE denotes how much weight loss would change overall if treatment assignment was changed from the self-paced to the counselor-initiated intervention. Table S7 in Multimedia Appendix 1 [44] contains the results of the sensitivity analysis; more details are provided in the GitHub repository [34]. 
Table 2. The 4- and 12-month mediation estimates the total effect, average direct effect (ADE), average causal mediation effect (ACME), and proportion mediated effect.

\begin{tabular}{lllll}
\hline Mediator & Total effect $(90 \% \mathrm{CI})$ & $\mathrm{ADE}^{\mathrm{a}}(90 \% \mathrm{CI})$ & $\mathrm{ACME}^{\mathrm{b}}(90 \% \mathrm{CI})$ & Proportion mediated, \% \\
\hline $\begin{array}{l}\text { 4-month mediation } \\
\quad \text { App-use }\left(\mathrm{PC}_{1}{ }^{\mathrm{a}}\right)\end{array}$ & $0.034(0.023$ to 0.045$)$ & $0.013(0.002$ to 0.025$)$ & $0.021(0.012$ to 0.029$)$ & 60.3 \\
$\quad \begin{array}{l}\text { Self-weighing frequency } \\
\text { 12-month mediation }\end{array}$ & $0.034(0.023$ to 0.045$)$ & $0.015(0.004$ to 0.026$)$ & $0.019(0.012$ to 0.027$)$ & 55.8 \\
$\quad$ 4-month weight loss & $0.032(0.015$ to 0.048$)$ & $0.002(-0.012$ to 0.031$)$ & $0.03(0.019$ to 0.043$)$ & 94.8 \\
\hline
\end{tabular}

${ }^{\mathrm{a}} \mathrm{PC}_{1}$ : principal component 1 .

\section{Weight Loss Predictions Through Linear Regression}

The cross-validated linear models built on baseline variables and electronically collected variables (ie, app-use $\left[\mathrm{PC}_{1}\right]$, app-calories $\left[\mathrm{PC}_{2}\right]$, app-exercise $\left[\mathrm{PC}_{3}\right]$, and self-weighing frequency) were first compared for weight loss prediction accuracy using 4-week data. For 4-month weight loss, the 8 -week model explained approximately $4 \%$ more variance than the model built on 4 -week data $\left(R^{2}=0.30\right.$ and 0.26 , respectively).
For 12-month weight loss, $R^{2}$ also slightly increased when 8 -week data were used compared with using 4-week data $\left(R^{2}=0.08\right.$ and 0.06 , respectively).

As results with 8-week data showed marginal improvement when compared with those using 4-week data, this study primarily focuses on analysis with 8 -week data. The results from the 8-week model performance are shown in Table 3. More information on the 4-week results and scatterplots of the models can be found in Multimedia Appendix 1.

Table 3. Accuracy of 8-week models for predicting 4-month and 12-month weight losses.

\begin{tabular}{|c|c|c|c|c|c|c|}
\hline \multirow[t]{2}{*}{ Model } & \multicolumn{3}{|c|}{ 4-month prediction } & \multicolumn{3}{|c|}{ 12-month prediction } \\
\hline & $R^{2}$ & $\rho$ & $\mathrm{mAUC}$ & $R^{2}$ & $\rho$ & mAUC \\
\hline Baseline variables (ie, age and treatment assignment) & 0.16 & 0.41 & 0.65 & 0.06 & 0.25 & 0.58 \\
\hline App-use $\left(\mathrm{PC}_{1}{ }^{\mathrm{b}}\right)+$ app-calories $\left(\mathrm{PC}_{2}^{\mathrm{c}}\right)+$ self-weighing frequency & 0.31 & 0.58 & 0.74 & 0.07 & 0.29 & 0.57 \\
\hline Baseline variables+app-use $\left(\mathrm{PC}_{1}\right)+$ app-calories $\left(\mathrm{PC}_{2}\right)+$ self-weighing frequency & 0.30 & 0.58 & 0.73 & 0.08 & 0.29 & 0.58 \\
\hline 4-month weight loss & $\mathrm{N} / \mathrm{A}^{\mathrm{d}}$ & N/A & N/A & 0.31 & 0.52 & 0.66 \\
\hline
\end{tabular}

${ }^{a}$ mAUC: multi-class area under the receiver operating characteristic curve.

${ }^{\mathrm{b}} \mathrm{PC}_{1}$ : principal component 1 .

${ }^{\mathrm{c}} \mathrm{PC}_{2}$ : principal component 2 .

${ }^{\mathrm{N}}$ /A: not applicable.

For 4-month predictions, cross-validation of only the baseline variables using a linear model resulted in modest $R^{2}$ and $\rho$ values $\left(R^{2}=0.16 ; \rho=0.41 ; \mathrm{AUC}=0.65\right)$. Adding the electronically collected variables (ie, app-use $\left[\mathrm{PC}_{1}\right]$, app-calories $\left[\mathrm{PC}_{2}\right]$, and self-weighing frequency at 8 weeks) to the model explained approximately $15 \%$ more variance than the baseline variables alone $\left(R^{2}=0.30 ; \rho=0.58 ; \mathrm{AUC}=0.73\right)$. The 12 -month predictions were less successful than the 4-month predictions when considering a combination of baseline variables and electronically collected variables (Table 3 ). Using all analysis variables only accounted for $8 \%$ of the variance in the data $(\rho=0.29 ; \mathrm{AUC}=0.58)$ for the 12 -month prediction. For both the 4-month and 12-month results, predictions based on only electronically collected variables tended to be slightly better

than the predictions from the models that included baseline variables. This suggests that treatment assignment and age do not improve out-of-sample prediction when technological variables are already in the model.

The final linear model predicting 4-month weight loss, summarized in Table 4, was generated with baseline variables, the app-use component, the app-calories component, and the frequency of self-weighing at 8 weeks. The model revealed that the components of app-use and app-calories as well as the frequency of weighing were significant at the $P=.01$ level. After accounting for these variables, treatment assignment and age were found to be not significant. The adjusted $R^{2}$ value for the model was 0.32 . If the app-exercise component $\left(\mathrm{PC}_{3}\right)$ was included, it was found to be not significant. 
Table 4. Linear regression model summary predicting 4-month weight loss with 8-week data.

\begin{tabular}{|c|c|c|c|}
\hline Coefficients & $\mathrm{b}(\mathrm{SE})$ & $t$ test $(d f)$ & $P$ value \\
\hline Intercept & $-1.89 \mathrm{E}-02(1.67 \mathrm{E}-02)$ & $-1.14(148)$ & .25 \\
\hline App-use $\left(\mathrm{PC}_{1}{ }^{\mathrm{a}}\right)$ & $4.51 \mathrm{E}-03(1.35 \mathrm{E}-03)$ & $3.34(148)$ & .001 \\
\hline App-calories $\left(\mathrm{PC}_{2}{ }^{\mathrm{b}}\right)$ & $6.20 \mathrm{E}-03(2.06 \mathrm{E}-03)$ & $3.01(148)$ & .003 \\
\hline Treatment assignment & $8.71 \mathrm{E}-03(7.30 \mathrm{E}-03)$ & $1.19(148)$ & .23 \\
\hline Age & $3.98 \mathrm{E}-04(3.97 \mathrm{E}-04)$ & $1(148)$ & .32 \\
\hline Self-weighing frequency at 8 weeks & $6.58 \mathrm{E}-04(2.41 \mathrm{E}-04)$ & $2.73(148)$ & .007 \\
\hline
\end{tabular}

${ }^{\mathrm{a}} \mathrm{PC}_{1}$ : principal component 1 .

${ }^{\mathrm{b}} \mathrm{PC}_{2}$ : principal component 2 .

For 12-month predictions (Table 5), the components of app-use and app-calories were not statistically significant predictors. Treatment assignment and the component of app-exercise were

also not significant. However, age and the frequency of self-weighing were significant predictors.

Table 5. Linear regression results predicting 12-month weight loss with 8-week data.

\begin{tabular}{|c|c|c|c|}
\hline Coefficients & $\mathrm{b}(\mathrm{SE})$ & $t$ test $(d f)$ & $P$ value \\
\hline Intercept & $-6.69 \mathrm{E}-02(2.62 \mathrm{E}-01)$ & $-2.55(147)$ & .01 \\
\hline App-use $\left(\mathrm{PC}_{1}{ }^{\mathrm{a}}\right)$ & $2.96 \mathrm{E}-03(2.05 \mathrm{E}-03)$ & $1.45(147)$ & .15 \\
\hline App-calories $\left(\mathrm{PC}_{2}{ }^{\mathrm{b}}\right)$ & 4.01E-03 (3.17E-03) & $1.26(147)$ & .21 \\
\hline Treatment assignment & $6.27 \mathrm{E}-03(1.12 \mathrm{E}-02)$ & $0.56(147)$ & .58 \\
\hline Age & $1.34 \mathrm{E}-03(6.08 \mathrm{E}-04)$ & $2.21(147)$ & .03 \\
\hline Self-weighing frequency at 8 weeks & 7.84E-04 (3.77E-04) & $2.08(147)$ & .04 \\
\hline
\end{tabular}

${ }^{\mathrm{a}} \mathrm{PC}_{1}$ : principal component 1 .

${ }^{\mathrm{b}} \mathrm{PC}_{2}$ : principal component 2 .

Although predicting 12-month weight loss with baseline and electronic data from the first 8 weeks resulted in low accuracy, using only 4-month weight loss as a predictor resulted in an $R^{2}$ of $0.31(\rho=.52$; multi-class $\mathrm{AUC}=.66)$.

\section{Discussion}

\section{Principal Findings}

Our results suggest that early study self-monitoring data, specifically PCs representing app use and self-monitoring of caloric intake and frequency of self-weighing, predict weight loss at 4 months, consistent with previous research indicating early self-monitoring predictors of treatment success $[17,19]$. Data from the first 8 weeks generated slightly more accurate weight loss predictions than data from the first 4 weeks; these results are consistent with those of Unick et al [20], who found that weight loss at 1 and 2 months was associated with 8 -year weight loss. Predicting 12-month weight loss using early study data proved to be more challenging; however, 4-month weight loss was predictive of 12-month weight loss, which follows the results of previous research that indicated that early weight change can predict long-term weight change [18,20,49].

Our mediation results (Table 2) showed that app-use and the frequency of self-weighing partially mediated the relationship between treatment assignment and weight loss during the first
4 months. This suggests that the intervention not only directly affected 4-month weight loss but also indirectly affected weight change through weighing and app use behavior. However, the intervention mainly had a short-term effect because the results demonstrate a full mediation effect on the association between treatment assignment and 12-month weight loss through the 4-month weight loss.

Predictive modeling results revealed consistent self-monitoring to be an important aspect of 4-month weight loss, which reflects the findings of many previous studies $[1,2]$. The decrease in app use over time also followed a similar pattern to previous findings in web-based and traditional self-monitoring studies $[19,50,51]$. Our descriptive results on the differences in logging trends between the treatment groups provide preliminary evidence that self-monitoring with regular feedback may improve self-monitoring consistency, which differs from the results of some previous studies that show that there is no difference in adherence between a treatment group that receives feedback and a group that receives no feedback [3].

The regression results also demonstrated that the PC representing exercise self-monitoring was not a significant predictor of short-term weight loss. Previous research has shown that exercise is more crucial in maintaining weight than losing weight [52-54]. Although we did not measure exercise (ie, the 
behavior) in the study, self-monitoring exercise seemed to add little benefit to short-term weight loss. Nonetheless, weight loss interventions should continue to encourage participants to increase their physical activity because of its role in weight maintenance; however, interventionists could focus on stressing the importance of self-monitoring caloric intake and self-weighing over monitoring exercise during the early intense weight loss period.

Overall, our results indicate that short-term weight loss leads to long-term weight loss, which is consistent with previous research. It is likely that the intervention establishes certain behaviors that induce weight loss at 4 months, some of which are continued at 12 months. The counselor-initiated condition seemed to establish more of these behaviors by 4 months, and the counselor-initiated-treatment participants were more successful at self-monitoring.

\section{Strengths and Limitations}

The strengths of the study include that it was a randomized clinical trial and one of the few studies that used data from a popular commercial app. In addition, the context of the randomized intervention study allowed us to conduct a causal mediation analysis to understand whether the intervention assignment directly and indirectly affected weight loss. Further, this is one of few weight control studies in the military.

By including a behavioral run-in period of dietary self-monitoring (as in previous studies [17]) in addition to requiring a medical clearance letter, it is possible that the participants may have been more motivated and well-informed about the study activities than those who did not complete these tasks. However, an examination of the characteristics of the randomized individuals compared with those of the individuals who were not randomized [27] showed that higher educational status was the only independent predictor of randomization. It is also interesting to note that it was initially expected that most of the participants would be motivated to join the study to assist them in passing the military fitness test. However, when the motivators for weight loss in this sample were examined, it was found that the most frequently endorsed motivators were improved physical health, improved fitness, improved quality of life, and a desire for longevity [55].

A limitation of using a commercial app in analysis is that the researchers have little control over the format in which they collect and receive data. In this study, a large portion of the nutrient information was not available because of the methods that the participants chose to log their calories. For instance, some participants logged calories directly without food description or nutrient details (eg, a lump sum of 2000 calories for the full day without further details); therefore, we were unable to use the nutrient reports in the analysis. We were also unable to include data from 57 participants because of technical errors in the data retrieval process because of a clerical mistake. This differential missingness between the 2 intervention conditions could have introduced bias; however, we note that the cause of the missing data was the data acquisition process and unrelated to the identity or behavior of the participants.

\section{Conclusions}

We found that long-term weight loss was completely mediated through short-term weight loss, reiterating the importance of interventions that produce strong successes quickly. Approximately one-third of the 12-month weight loss was explained by weight loss at 4 months. More than half of the effect of the behavioral intervention on weight loss at 4 months was mediated through self-monitoring app use and self-weighing frequency, indicating the potency of these self-regulatory behaviors. As we did not find evidence of an effect of self-monitored exercise, it suggests that diet self-monitoring should be prioritized for successful weight loss.

\section{Acknowledgments}

This research represents a collaborative research and development agreement with the United States Air Force (CRADA \#13-168-SG-C13001). This study was also partially funded by the National Institute of Diabetes and Digestive and Kidney Diseases (RO1 DK097158; principal investigators: RK and RCK). The opinions expressed in this document are solely those of the authors and do not represent an endorsement by, or the views of, the United States Air Force, the Department of Defense, or the United States Government. We would like to thank the participants, the leadership at Second Air Force, and the research staff for their dedication to the research. We gratefully acknowledge the partnership with Lose It! and Body Trace.

\section{Conflicts of Interest}

None declared.

\section{Multimedia Appendix 1}

Supplemental analysis tables.

[DOCX File, 50 KB-Multimedia Appendix 1]

\section{References}

1. Boutelle K, Kirschenbaum D. Further support for consistent self-monitoring as a vital component of successful weight control. Obes Res 1998 May;6(3):219-224 [FREE Full text] [doi: 10.1002/j.1550-8528.1998.tb00340.x] [Medline: 9618126]

2. Baker RC, Kirschenbaum DS. Self-monitoring may be necessary for successful weight control. Behav Ther 1993;24(3):377-394. [doi: 10.1016/S0005-7894(05)80212-6] 
3. Burke LE, Conroy MB, Sereika SM, Elci OU, Styn MA, Acharya SD, et al. The effect of electronic self-monitoring on weight loss and dietary intake: a randomized behavioral weight loss trial. Obesity 2011 Feb;19(2):338-344 [FREE Full text] [doi: 10.1038/oby.2010.208] [Medline: 20847736]

4. Cussler EC, Teixeira PJ, Going SB, Houtkooper LB, Metcalfe LL, Blew RM, et al. Maintenance of weight loss in overweight middle-aged women through the Internet. Obesity 2008 May;16(5):1052-1060 [FREE Full text] [doi: 10.1038/oby.2008.19] [Medline: 18309301$]$

5. Spring B, Duncan JM, Janke EA, Kozak AT, McFadden HG, DeMott A, et al. Integrating technology into standard weight loss treatment: a randomized controlled trial. JAMA Intern Med 2013 Jan 28;173(2):105-111 [FREE Full text] [doi: 10.1001/jamainternmed.2013.1221] [Medline: 23229890]

6. Allen JK, Stephens J, Himmelfarb CR, Stewart KJ, Hauck S. Randomized controlled pilot study testing use of smartphone technology for obesity treatment. J Obes 2013;2013:151597 [FREE Full text] [doi: 10.1155/2013/151597] [Medline: 24392223]

7. West JH, Belvedere LM, Andreasen R, Frandsen C, Hall PC, Crookston BT. Controlling your 'App'Etite: how diet and nutrition-related mobile apps lead to behavior change. JMIR Mhealth Uhealth 2017 Jul 10;5(7):e95 [FREE Full text] [doi: 10.2196/mhealth.7410] [Medline: 28694241]

8. Laing BY, Mangione CM, Tseng C, Leng M, Vaisberg E, Mahida M, et al. Effectiveness of a smartphone application for weight loss compared with usual care in overweight primary care patients: a randomized, controlled trial. Ann Intern Med 2014 Nov 18;161(10 Suppl):S5-12 [FREE Full text] [doi: 10.7326/M13-3005] [Medline: 25402403]

9. Harvey J, Krukowski R, Priest J, West D. Log often, lose more: electronic dietary self-monitoring for weight loss. Obesity 2019 Mar;27(3):380-384 [FREE Full text] [doi: 10.1002/oby.22382] [Medline: $\underline{30801989}$ ]

10. How Lose It! Is Helping Real People. Lose It. 2019. URL: http://www.webcitation.org/77f0LbIKt [accessed 2019-04-15]

11. Baer SK. 150 Million Users Of The MyFitnessPal App Had Their Data Stolen By A Third Party. BuzzFeed News. 2018. URL: https://www.buzzfeednews.com/article/skbaer/myfitnesspal-under-armour-data-stolen [accessed 2019-04-14]

12. Burke LE, Wang J, Sevick MA. Self-monitoring in weight loss: a systematic review of the literature. J Am Diet Assoc 2011 Jan;111(1):92-102 [FREE Full text] [doi: 10.1016/j.jada.2010.10.008] [Medline: 21185970]

13. Zheng Y, Klem ML, Sereika SM, Danford CA, Ewing LJ, Burke LE. Self-weighing in weight management: a systematic literature review. Obesity 2015 Feb;23(2):256-265 [FREE Full text] [doi: 10.1002/oby.20946] [Medline: 25521523]

14. Vanwormer JJ, French SA, Pereira MA, Welsh EM. The impact of regular self-weighing on weight management: a systematic literature review. Int J Behav Nutr Phys Act 2008 Nov 4;5:54. [doi: 10.1186/1479-5868-5-54] [Medline: 18983667]

15. Steinberg DM, Bennett GG, Askew S, Tate DF. Weighing every day matters: daily weighing improves weight loss and adoption of weight control behaviors. J Acad Nutr Diet 2015 Apr;115(4):511-518 [FREE Full text] [doi: 10.1016/j.jand.2014.12.011] [Medline: 25683820]

16. Zheng Y, Sereika SM, Ewing LJ, Danford CA, Terry MA, Burke LE. Association between self-weighing and percent weight change: mediation effects of adherence to energy intake and expenditure goals. J Acad Nutr Diet 2016 Apr;116(4):660-666 [FREE Full text] [doi: 10.1016/j.jand.2015.10.014] [Medline: 26727241]

17. Tsai AG, Fabricatore AN, Wadden TA, Higginbotham AJ, Anderson A, Foreyt J, et al. Readiness redefined: a behavioral task during screening predicted 1-year weight loss in the look AHEAD study. Obesity 2014 Apr;22(4):1016-1023 [FREE Full text] [doi: 10.1002/oby.20648] [Medline: 24151217]

18. West DS, Harvey-Berino J, Krukowski RA, Skelly JM. Pretreatment weight change is associated with obesity treatment outcomes. Obesity 2011 Sep;19(9):1791-1795 [FREE Full text] [doi: 10.1038/oby.2011.22] [Medline: 21331064]

19. Krukowski RA, Harvey-Berino J, Bursac Z, Ashikaga T, West DS. Patterns of success: online self-monitoring in a web-based behavioral weight control program. Health Psychol 2013 Feb;32(2):164-170 [FREE Full text] [doi: 10.1037/a0028135] [Medline: 22545978]

20. Unick JL, Neiberg RH, Hogan PE, Cheskin LJ, Dutton GR, Jeffery R, Look AHEAD Research Group. Weight change in the first 2 months of a lifestyle intervention predicts weight changes 8 years later. Obesity 2015 Jul;23(7):1353-1356 [FREE Full text] [doi: 10.1002/oby.21112] [Medline: 26110890]

21. Johnston CA, Moreno JP, Foreyt JP. Cardiovascular effects of intensive lifestyle intervention in type 2 diabetes. Curr Atheroscler Rep 2014 Dec;16(12):457 [FREE Full text] [doi: 10.1007/s11883-014-0457-6] [Medline: 25288176]

22. Wadden TA, West DS, Delahanty L, Jakicic J, Rejeski J, Williamson D, Look AHEAD Research Group. The Look AHEAD study: a description of the lifestyle intervention and the evidence supporting it. Obesity 2006 May;14(5):737-752 [FREE Full text] [doi: 10.1038/oby.2006.84] [Medline: 16855180]

23. Look AHEAD Research Group, Pi-Sunyer X, Blackburn G, Brancati FL, Bray GA, Bright R, et al. Reduction in weight and cardiovascular disease risk factors in individuals with type 2 diabetes: one-year results of the look AHEAD trial. Diabetes Care 2007 Jun;30(6):1374-1383 [FREE Full text] [doi: 10.2337/dc07-0048] [Medline: 17363746]

24. Krukowski RA, Hare ME, Talcott GW, Johnson KC, Richey PA, Kocak M, et al. Dissemination of the look AHEAD intensive lifestyle intervention in the United States Air Force: study rationale, design and methods. Contemp Clin Trials 2015 Jan;40:232-239 [FREE Full text] [doi: 10.1016/j.cct.2014.12.014] [Medline: 25545025] 
25. Krukowski RA, Hare ME, Talcott GW, Gladney LA, Johnson KC, Richey PA, et al. Dissemination of the look AHEAD intensive lifestyle intervention in the United States Military: a randomized controlled trial. Obesity 2018 Oct;26(10):1558-1565 [FREE Full text] [doi: 10.1002/oby.22293] [Medline: 30277030]

26. Weight Loss That Fits. Lose It. 2018. URL: http://www.webcitation.org/73rfgQDPz [accessed 2018-11-12]

27. Fahey M, Hare ME, Talcott GW, Kocak M, Hryshko-Mullen A, Klesges RC, et al. Characteristics associated with participation in a behavioral weight loss randomized control trial in the U.S. Military. Mil Med 2019 Mar 1;184(3-4):e120-e126 [FREE Full text] [doi: 10.1093/milmed/usy199] [Medline: 30125001]

28. Williamson DA, Bray GA, Ryan DH. Is $5 \%$ weight loss a satisfactory criterion to define clinically significant weight loss? Obesity (Silver Spring) 2015 Dec;23(12):2319-2320 [FREE Full text] [doi: 10.1002/oby.21358] [Medline: 26523739]

29. Wing RR, Tate DF, Gorin AA, Raynor HA, Fava JL. A self-regulation program for maintenance of weight loss. N Engl J Med 2006 Oct 12;355(15):1563-1571. [doi: 10.1056/NEJMoa061883] [Medline: 17035649]

30. Kocak M, Krukowski R, Talcott G. Processing, Cleaning, and Streaming data in SAS. PharmaSUG. 2018. URL: http://web. archive.org/web/20201124054222/www.pharmasug.org/proceedings/2018/DV/PharmaSUG-2018-DV11.pdf [accessed 2019-08-20]

31. Jeon KJ, Lee O, Kim H, Han SN. Comparison of the dietary intake and clinical characteristics of obese and normal weight adults. Nutr Res Pract 2011 Aug;5(4):329-336 [FREE Full text] [doi: 10.4162/nrp.2011.5.4.329] [Medline: 21994528]

32. The R Project for Statistical Computing. URL: https://www.R-project.org/ [accessed 2019-07-31]

33. Tidyverse: Easily Install and Load the Tidyverse. 2017. URL: https://tidyverse.tidyverse.org/ [accessed 2019-08-01]

34. Farage G, Gale1 C, Kocak M, Klesges RC, Talcott GW, Richey P, et al. Assessing the contribution of self-monitoring through a commercial weight loss app: mediation and predictive modeling. GitHub, Inc. 2021. URL: https://github.com/ senresearch/dietappstudy [accessed 2021-06-23]

35. Vatcheva KP, Lee M, McCormick JB, Rahbar MH. Multicollinearity in regression analyses conducted in epidemiologic studies. Epidemiology (Sunnyvale) 2016 Apr;6(2):- [FREE Full text] [doi: 10.4172/2161-1165.1000227] [Medline: 27274911]

36. Jolliffe I, Cadima J. Principal component analysis: a review and recent developments. Philos Trans A Math Phys Eng Sci 2016 Apr 13;374(2065):20150202 [FREE Full text] [doi: 10.1098/rsta.2015.0202] [Medline: 26953178]

37. Ringnér M. What is principal component analysis? Nat Biotechnol 2008 Mar;26(3):303-304. [doi: 10.1038/nbt0308-303] [Medline: 18327243]

38. Lê S, Josse J, Husson F. FactoMinerR a package for multivariate analysis. J Stat Soft 2008;25(1):1-18. [doi: 10.18637/jss.v025.i01]

39. Factoextra: Extract and Visualize the Results of Multivariate Data Analyses Analysis. The Comprehensive R Archive Network. 2017. URL: https://cran.r-project.org/web/packages/factoextra [accessed 2019-08-16]

40. Imai K, Yamamoto T. Identification and sensitivity analysis for multiple causal mechanisms: revisiting evidence from framing experiments. Polit Anal 2017 Jan 4;21(2):141-171. [doi: 10.1093/pan/mps040]

41. MacKinnon DP, Fairchild AJ, Fritz MS. Mediation analysis. Annu Rev Psychol 2007;58:593-614 [FREE Full text] [doi: 10.1146/annurev.psych.58.110405.085542] [Medline: 16968208]

42. Imai K, Keele L, Tingley D. A general approach to causal mediation analysis. Psychol Methods 2010 Dec;15(4):309-334. [doi: 10.1037/a0020761] [Medline: 20954780]

43. Tingley D, Yamamoto T, Hirose K, Keele L, Imai K. Mediation: R package for causal mediation analysis. J Stat Soft 2014;59(5):1-38. [doi: 10.18637/jss.v059.i05]

44. Imai K, Keele L, Tingley D. A general approach to causal mediation analysis. Psychol Methods 2010 Dec;15(4):309-334. [doi: 10.1037/a0020761] [Medline: 20954780]

45. VanderWeele T, Vansteelandt S. Mediation analysis with multiple mediators. Epidemiol Methods 2014 Jan;2(1):95-115 [FREE Full text] [doi: 10.1515/em-2012-0010] [Medline: 25580377]

46. Daniel RM, de Stavola BL, Cousens SN, Vansteelandt S. Causal mediation analysis with multiple mediators. Biometrics 2015 Mar 28;71(1):1-14 [FREE Full text] [doi: 10.1111/biom.12248] [Medline: 25351114]

47. Jerolon A, Baglietto L, Birmele E, Perduca V, Alarcon F. Causal Mediation Analysis in Presence of Multiple Mediators Uncausally Related. arXivstat. 2018. URL: https://arxiv.org/abs/1809.08018 [accessed 2020-06-12]

48. Jed WM, Weston S, Williams A, Keefer C, Engelhardt A, Cooper T. Caret: Classification and Regression Training. The Comprehensive R Archive Network. 2018. URL: https://CRAN.R-project.org/package=caret [accessed 2020-09-19]

49. Varkevisser RD, van Stralen MM, Kroeze W, Ket JC, Steenhuis IH. Determinants of weight loss maintenance: a systematic review. Obes Rev 2019 Feb 16;20(2):171-211 [FREE Full text] [doi: 10.1111/obr.12772] [Medline: 30324651]

50. Peterson ND, Middleton KR, Nackers LM, Medina KE, Milsom VA, Perri MG. Dietary self-monitoring and long-term success with weight management. Obesity (Silver Spring) 2014 Sep 13;22(9):1962-1967 [FREE Full text] [doi: 10.1002/oby.20807] [Medline: 24931055]

51. Pellegrini CA, Conroy DE, Phillips SM, Pfammatter AF, McFadden H, Spring B. Daily and seasonal influences on dietary self-monitoring using a smartphone application. J Nutr Educ Behav 2018 Jan;50(1):56-61.e1 [FREE Full text] [doi: 10.1016/j.jneb.2016.12.004] [Medline: 29325663] 
52. Swift DL, Johannsen NM, Lavie CJ, Earnest CP, Church TS. The role of exercise and physical activity in weight loss and maintenance. Prog Cardiovasc Dis 2014;56(4):441-447 [FREE Full text] [doi: 10.1016/j.pcad.2013.09.012] [Medline: 24438736]

53. Miller WC, Koceja DM, Hamilton EJ. A meta-analysis of the past 25 years of weight loss research using diet, exercise or diet plus exercise intervention. Int J Obes Relat Metab Disord 1997 Oct;21(10):941-947. [doi: 10.1038/sj.ijo.0800499] [Medline: 9347414]

54. Pronk NP, Wing RR. Physical activity and long-term maintenance of weight loss. Obes Res 1994 Nov;2(6):587-599 [FREE Full text] [doi: 10.1002/j.1550-8528.1994.tb00110.x] [Medline: $\underline{\text { 16358405] }}$

55. Maclin-Akinyemi C, Krukowski RA, Kocak M, Talcott GW, Beauvais A, Klesges RC. Motivations for weight loss among active duty military personnel. Military Medicine 2017 Sep;182(9):e1816-e1823 [FREE Full text] [doi: $\underline{10.7205 / \text { milmed-d-16-00380] }}$

\author{
Abbreviations \\ ACME: average causal mediation effect \\ AHEAD: Action for Health in Diabetes \\ AUC: area under the receiver operating characteristic curve \\ PC: principal component \\ PCA: principal component analysis \\ TE: total effect
}

\author{
Edited by $G$ Eysenbach, $Q$ Zeng; submitted 16.03.20; peer-reviewed by A Beleigoli, A Andrade, BT Nezami; comments to author \\ 28.08.20; revised version received 22.12.20; accepted 15.04.21; published 14.07.21 \\ Please cite as: \\ Farage G, Simmons C, Kocak M, Klesges RC, Talcott GW, Richey P, Hare M, Johnson KC, Sen S, Krukowski R \\ Assessing the Contribution of Self-Monitoring Through a Commercial Weight Loss App: Mediation and Predictive Modeling Study \\ JMIR Mhealth Uhealth 2021;9(7):e18741 \\ URL: https://mhealth.jmir.org/2021/7/e18741 \\ doi: $\underline{10.2196 / 18741}$ \\ PMID: 34259635
}

(C) Gregory Farage, Courtney Simmons, Mehmet Kocak, Robert C Klesges, G Wayne Talcott, Phyllis Richey, Marion Hare, Karen C Johnson, Saunak Sen, Rebecca Krukowski. Originally published in JMIR mHealth and uHealth (https://mhealth.jmir.org), 14.07.2021. This is an open-access article distributed under the terms of the Creative Commons Attribution License (https://creativecommons.org/licenses/by/4.0/), which permits unrestricted use, distribution, and reproduction in any medium, provided the original work, first published in JMIR mHealth and uHealth, is properly cited. The complete bibliographic information, a link to the original publication on https://mhealth.jmir.org/, as well as this copyright and license information must be included. 